\title{
HOW TO TRANSFER A COUPON-BASED EVENT INTO A HEDONIC SHOPPING EXPERIENCE? RETAIL BRANDING IMPLICATIONS BASED ON THE GLAMOUR SHOPPING DAYS
}

\author{
ZITA KELEMEN $^{1}$ - PÉTER NAGY ${ }^{2}$ - ILDIKÓ KEMÉNY ${ }^{3}$ \\ ${ }^{1}$ Assistant Professor, Corvinus University of Budapest, Institute of Marketing and Media \\ E-mail: zita.kelemen@uni-corvinus.hu \\ ${ }^{2}$ Corvinus University of Budapest, Institute of Marketing and Media \\ E-mail:peter.nagy@uni-corvinus.hu \\ ${ }^{3}$ Researcher, Corvinus University of Budapest, Institute of Marketing and Media \\ E-mail: ildiko.kemeny@uni-corvinus.hu
}

\begin{abstract}
The paper examines the motivational drivers behind the participation of Hungarian consumers on a special shopping event, also known as Glamour Days. The study encompasses a variety of related conceptualizations such as hedonic/utilitarian shopping values, self-gifting as well as impulsive buying practices. After the introduction of relevant consumer behaviour concepts and theoretical frameworks, the paper presents a qualitative research on adult and adolescent female consumers' shopping experiences during Glamour Days. By building on phenomenological methodology, this study also portrays the ways this shopping event has changed consumer society within an originally strongly utilitarian attitude driven Hungarian culture. The phenomenological interview results highlight differences within the motivational drivers of pleasure-oriented shopping for the two age groups. For teenagers, the main motivation was related to the utilitarian aspect due to their financial dependence and the special opportunity to stand out of their peer group by joining an event that is exclusively held for adult women. On the other hand, adult women are motivated by combined hedonic and utilitarian values manifested in self gifting and impulse buying within an effectively planned and managed shopping trip. Based on the results, retail specific strategies are provided along with future research directions.
\end{abstract}

Keywords: consumer behaviour, retail strategy, hedonic, utilitarian, shopping

JEL-codes: M16, M31 


\section{Introduction}

The motivational aspects of consumer decision making generated high levels of interest as the economic downturn forced retailers and companies alike to get a deeper insight into concepts that investigate the drivers of consumers to the lucrative practices of self-indulgence. Previous research focused on several components of consumer shopping behaviour, such as selfindulgent, pleasure seeking shopping experience as well as, the functional utilitarian purchases (Babin et al. 1994), but few concentrated on the role of women in consumption practices. Neuner at al. (2005, in Bauer - Mitev 2012) "found a growing tendency in the previous East Germany, where the tendency to compulsively buying has increased much faster than in the Western part, probably due to the recent exposure to consumer culture." Droge and Mackoy (1995) suggested that compulsive buying, as a driver to become a part of the Hungarian consumer society should be considered. Other research investigated the change in consumer society in the transitional period in Hungary. Coulter et al. (2005) describe the change within the Hungarian consumer society reflecting an increasing importance of appearance and cosmetics and a higher value dedicated to advertising especially in fashion magazines.

In 2005, the Hungarian edition of Glamour Fashion Magazine announced a coupon weekend called Glamour Days, an exclusive event for women interested in fashion. Glamour Days was the first of its kind in Hungary, providing an opportunity for consumers to purchase imagerelated products at a discount within an organized weekend retail event and drawing enormous crowds to malls. Glamour Days offer " $20-25-50 \%$ off” coupons for many of the most popular brands. This unique phenomenon changed the context of the shopping experience mostly related to hedonistic, symbolic self-enhancing product categories such as clothing, accessories, make-up and shoes, thus directly effecting consumer psychology and behaviour.

There has been no research done on understanding the shared culture of this group of consumers. Although Coulter et al. (2005: 616) suggest that "manufacturers and retailers might work together to encourage shopping with friends or acquaintances who have either product category or marketplace expertise." Glamour days fills the void for the above mentioned criteria. The present study aimed at gaining a better understanding of the motivational changes in the shopping experience provided by the phenomenon called Glamour Days. After introducing relevant consumer behaviour concepts, such as hedonic consumption, self-gifting and impulsive buying, the paper introduces a qualitative research on 
adult and adolescent female consumers' shopping experiences during Glamour Days. By building on phenomenological methodology, this study also portrays the ways this shopping event has changed the consumer society within an originally strongly utilitarian attitude driven Hungarian culture (Millan - Howard 2007). The descriptive knowledge gained from an interpretive investigation of a retail phenomenon, which generates growth by changing consumer behaviour, can be used to support retail strategy formulation also on a multicultural basis. The study develops the notion of a unique shared consumption culture which combines elements of social context with utilitarian aspects to create contextual synthesis in each theme.

\section{Literature review}

Investigating the importance of Glamour Days shopping experience lies not only within its financial and retail success, but moreover in confirming the changing cultural ideologies in Central Europe, which resulted in higher importance of appearance and cosmetics for women also in "pronounced effects on women's interpersonal relationships." (Coulter 2003:165). The author calls for additional study with a focus on the changing nature of role relationships, role reversals, and related emotional tensions and their impact on consumption patterns.

Consumers shop in fulfilment of certain life roles such as being a "good friend" or a "good spouse" (Wagner - Rudolph 2010; Tauber 1972). Life Themes, "existential concerns that individuals address in everyday life eg. being cosmopolitan" and Life Projects, the construction and maintenance of key life roles and identities eg. being a responsible mother" (Huffman et al. 2000:15, 18), are shaped and modified by cultural ideologies and significantly rooted in personal history and social networks. Product consumption practices are linked to current Life Projects by which emotional or functional needs are satisfied. In this sense, products are no longer viewed as uni-dimensional in nature, but instead are categorised as either utilitarian, fulfilling functional, instrumental, practical and non-sensory needs, or hedonic, addressing affective gratification, enjoyment and experiential benefits (Chitturi et al. 2008; Hirschman - Holbrook 1982; Sivadas - Venkatesh 1995; Voss et al. 2003). In the following, we briefly present the theory of hedonic consumption, and two related contexts, namely self-gifting and impulsive buying (Woodruffe-Burton - Wakenshaw 2002).

Hirschman and Holbrook (1982: 92) defined hedonic consumption as a central factor that "designates those facets of consumer behavior that relate to the multi-sensory, fantasy and emotive aspects of one's experience with products." Previous research highlighted that 
hedonic consumption is closely related to pleasure-seeking and pleasure-maximizing (Alba Williams 2013); multisensory images, fantasies and emotional arousal (Arnold - Reynolds, 2012); avoiding negative, guilt-related emotions (Goldsmith et al. 2012) as well as pursuing happiness (Zhong - Mitchell 2012). Furthermore, consumers tend to seek hedonic experiences for their stimulative and experiential qualities (Wakefield - Baker 1998). Compared to utilitarian consumption which is a task-related and rational activity (Dhar - Wertenbroch 2000), hedonic consumption is considered a more subjective and personal experience. Shopping in some cases may provide hedonistic and utilitarian value at the same time (Belk 1987; Fischer - Arnold 1990; Sherry 1983), in other cases, one may inhibit the presence of the other. For instance, bargain perceptions can provide positive sensory perceptions resulting in emotional value (Babin et al. 1994), while other hedonic value related elements such as heightened affect may interfere with harder task performance and lead to low utilitarian value (Eroglu - Harrell 1986, in Babin et al. 1994). Hedonic consumption is also related to selfgifting practices that help consumers to justify prior purchases and reward themselves (Mick DeMoss 1990).

The multi-dimensional construct of self-gifting captures therapeutic, rewarding, celebratory and hedonic aspects, in relation to a wide range of categories, such as fast food, music, entertainment and personal care (Clarke - Mortimer 2013; Mick - DeMoss 1990). Clarke and Mortimer (2013: 473) defines self-gifting as a process that is associated with the purchase of services or products where the "consumption is internally attributed, exclusively personal, pleasure oriented and independent of an immediate need." Although research in this area continues to be relatively scarce, there has been an increasing amount of emphasis on the meaning and relevance associated with self-gifting by consumers experiencing different situations and life events (Ward - Thuhang 2007; Heath et al. 2011; Rohatyn 1990). Selfgifting is often associated with hedonic and indulgent drivers that are filled with variety, novelty and surprise (Holbrook - Hirschman 1982). Both internal and external motivations tend to exert a notable influence, separately as well as in combination. More specifically, although the initial trigger to engage in the act of self-gifting may originate from personal aspirations and self-related motives, the actual purchase of luxury products as self-gifts tends to be driven predominantly by social considerations (Kauppinen - Räisänen 2014). Clarke and Mortimer (2013) argue that self-gifts may fulfill hedonic needs encompassing a great number of factors, such as being nice to oneself or immersing in memorable and lasting experience. 
Deservedness, associated with most self-gifting practices (Mick - DeMoss 1990; Heath et al. 2011), may represent a way to escape from everyday life or finding a pleasure oriented experience to relieve stress (Carpenter - Moore 2009). Many self gifts serve not only as an emotional facet of hedonistic purchasing, but enable the consumer to re-experience these feelings through subsequent product usage (Mick et al. 1992). Interestingly, females and nonmarried individuals have been found to be more likely to engage in self-gifting; most of them without subsequent dissonance (Ward - Thuhang 2007).

Prior research revealed that pleasure oriented consumers buy because "it feels good" (Rohatyn 1990; Mick - DeMoss 1990). Tauber (1972) argued that self-gratification may be a motive for buying oneself something nice. This phenomenon suggests additional traits of hedonistic shopping such as self-indulgence and impulse shopping. The psychological conflict that sometimes arises from consumer's choices between saving and impulsive spending (Rook 1987) cannot be maintained in relation with self-indulgent and hedonistic shopping practices, as they did not encourage post purchase regret (Clarke - Mortimer 2013). Controlling the inner urge to buy something is closely related to the philosophical concept of will power. The ability to delay immediate gratification may lead to substantial psychological disequilibrium for the customer. Therefore some people "plan on being impulsive" in order to maintain some control over the impulsive urge (Rook 1985). In case of self-gifting, post-purchase regret can surface, but is more likely to occur following celebratory or therapeutic self-gifting motivations rather than those that are linked with reward or hedonic considerations (Clarke Mortimer 2013).

Finally, the notion of impulsive or impulse buying represents a departure from the pathological states of addiction and compulsive consumption, capturing compensatory behaviours that fall under the realm of regular shopping as opposed to a psychiatric condition (Coley - Burgess 2003; Rook, 1987). Synthesizing earlier conceptualizations, a comprehensive definition was offered by Sharma, Sivakumaran, and Marshall (2010: 277), who suggest that impulsive buying is a "sudden, hedonically complex purchase behaviour in which the rapidity of the impulse purchase precludes any thoughtful, deliberate consideration of alternative or future implications." Impulse buying tends to possess a strongly positive emotional charge (Bashar et al. 2013; Brici et al. 2013), and is mostly accompanied by loweffort and affective decision-making (Holbrook - Hirschman 1982). Individuals engaging themselves in impulse purchase tend to be driven by a temporary yet powerful temptation for 
immediate gratification, that is often followed by justification and/or regret (Bayley Nancarrow 1998). A powerful strategy to avoid a possible substantial psychological disequilibrium related to immediate gratification is the delay of gratification or the act of "planning on being impulsive" in order to maintain some control over the impulsive urge (Rook 1985).

\section{Methodology}

The study's research method was an interpretivist methodological approach in order to develop an understanding of the complexity of the Glamour Days shopping phenomenon. Other consumer studies that have adopted a phenomenological position include Thomson's (Thompson et al. 1990) study on gender roles, or Mick and DeMoss's (1990) on self gifting. By using phenomenological interviewing techniques the authors were able to gain in-depth insights into multiple perspectives on the "lived experience" (Spiegelberg 1982). According to Hycner (1999:156) "the phenomenon dictates the method (not vica-versa) including even the type of participants". Therefore, purposive sampling was undertaken. Participants were selected based on personal judgement and the purpose of the research (Greig - Taylor 1999). Invitations to participate in the research were sent to blog writers after careful content analysis of their blogs focusing on posts about personal experience on Glamour Days. Other participants were recruited by using the snowball sampling method. Boyd (2001) suggests 210 participants as sufficient to reach saturation, and so does Creswell $(1998: 65,113)$ by recommending "long interview up to 10 people". As a result, 9 women between the age of 25 40 and 9 teenagers of age 15-18 were chosen with a history of multiple visits to this event.

Unstructured in-depth interviews varied in length between 45-90 minutes, and were conducted the week after the Glamour Days shopping weekend. Following phenomenological principles, a seven step process suggested by Coalizzi (1978) was used to ensure proper analysis of the data. After reading the narratives, the authors extracted "significant statements" to be isolated into themes. It also served the goal to become familiar with the participants' expressions used in describing the experience. In formulation of themes, the authors have created clusters to group together similar meanings appearing in the narratives (Creswell 1998). The emerging themes were structured in a way to offer a holistic context for the Glamour Days shopping phenomenon by reconstructing the inner world of the experience. Beside the occurring collective themes, individual themes that were unique to one or few participants were also noted. Validity check was performed by returning to the interviewees to 
determine whether the main themes of the interview were correctly captured. For the validation of the importance of Glamour Days in retail calendars in Hungary, three in-depth interviews were made. Two were conducted with the most important participating brands with the marketing manager of H\&M (clothing) and marketing manager and owner of The Bodyshop (cosmetics) to understand the motivation behind joining a coupon driven sales event.

\section{Discussion}

\subsection{Glamour days as experiential shopping}

A coupon based shopping event may suggest hedonic shopping value generated by the economic savings, but for Glamour Days, participants also expected to gain positive experience from the event itself. All adult interviewees reported that Glamour Days generated an emotional response as referred below.

Since I have a child, I seldom go shopping, but the Glamour Days is the only time when I really go shopping. (Timi, 32)

Two of the main themes, emerging from the adult phenomenological interviews, encapsulated the hedonic and utilitarian value of the Glamour Days shopping experience. It provides an opportunity to escape from everyday life and realize a Life Theme of "being cosmopolitan". Participants also considered Glamour Days as a day dedicated for themselves and shopping, but also considered the task related approach of being efficient as reported below.

My Glamour day shopping is functional and enjoyable at the same time. I love shopping. [...] Shopping helps me relieve the stress. It is a good feeling, but it does not exclude to be also goal oriented and effective. This day is not about spending hours just looking around, that is also good, but here you have to use the coupons. (Rita, 28)

Participants tended to feel that they are under time pressure, and reported to be spending a great amount of time on preparation in order to ensure that the day was "perfect". They are awaiting to this event which was highlighted as a hedonistic, emotional shopping trip. All interviewees shared their experience already starting preparations weeks before by buying the magazine, browsing in malls or even trying on clothes in advance.

I go the day before to try the clothes on or even a week before, and to see which shops have my size, so on Friday I only have to take the rack and go to the cashier. (Rita, 28) 
I always cut out the interesting coupons before and even organize it in alphabetical order [according to the name of the shop/brand]. (Eszter 26)

The above dichotomy of experience of the event is also present among adolescents, but related to different motivational drivers. Young adults in particular tended to view Glamour Days as an opportunity to be apart from their families and make economic decisions on their own. They really enjoyed Glamour Days for being able to take part in an exclusive event where they could buy clothes and makeup at a reduced price. Contrary to the adults, adolescents did not consider Glamour Days as a perfect day dedicated for themselves, but rather as an event that only some of their peers know about, and therefore by participating they could become members of an exclusive consumer community. In other words, by attending Glamour Days, adolescents may feel that they are special, unique and distinguished members of their peer group.

I think my peers do not know about Glamour Days... I mean the students who I know here are ignorant and they do not read blogs or fashion magazines. They just tend to live their boring lives and focus on their own business. (Rebeka, 18)

\subsection{The social aspect of Glamour Days}

Interestingly, time management appeared to be an important characteristic of the Glamour Days experience strongly supporting the utilitarian value of it. However Glamour Days shopping also has a social context. In our study, several women reported that they engage in social interaction. This motive has two significant dimensions. First, they carefully choose people to accompany them or rather go alone. Choosing companions with similar tastes and attitudes is an important part of the strategy to maximize the experience. "Waiting for others" may be considered annoying as exemplified below:

Because I have very few chances to go shopping, I choose friends to go with, who like the same shops as I do, and therefore say, will not waste my time having to go into shops I don't want to. (Timi, 32) 
I try to reduce the number of friends that I go with, because we keep each other up [...] I like to go with my sister, as our taste is similar and she is also not the "can't make up my mind" type. She knows what she wants and decides. (Barbara, 26)

One participant explicitly mentioned that she likes going shopping with her friends, but not on Glamour Days. $60 \%$ of the respondents reported "role reciprocity", going with their Mom to help her make decisions and spend quality time with her as described hereafter:

I like shopping with my Mom a lot. I always choose clothes for her, she tries them on and realizes how well they fit. I am happy if she joins. (Gabi, 28)

The second unique theme of the social interaction, which cannot be related to other shopping trips, was identified as: cooperation with other customers. Adult respondents articulated that they enjoy cooperating with other customers. Considering the fact that these coupons have to be bought with the magazine in advance and there is a restricted supply, it is interesting that giving away or sharing coupons is a common practice. These results suggest that there is ambiguity between two major themes, in choosing to go alone and the strong underlying need of sharing the happiness and good mood generated by the Glamour Days shopping experience with others.

I often go with my friend, and give away coupons to complete strangers if we see they need them. It also happened that we came home from Vienna with my brother, and we did not know that there were Glamour days, so we asked for coupons from others. (Timi, 32)

For young adults and teenagers, Glamour Days are primarily social events, rather than economic ones, that involve a wide range of social activities, such as meeting their friends before Glamour Days or talking with them at fast-food restaurants after shopping. In this sense, they consider Glamour Days as a unique opportunity to spend some time with their friends and peers, and have a good time during shopping. Our results suggest that although adolescents and young adults focus on the utilitarian aspects of Glamour Days, such as lower prices and other discounts, they also have a strong desire for company that helps them gain positive emotions when it comes to shopping. 
Well, I like Glamour Days because I can buy clothes or accessories at reduced prices. I think Glamour Days are about... you know... you can buy clothes and your favourite brands, and you may use coupons to buy them cheaper. Oh, and I always read through the coupon magazine and collect the ones that seem interesting to me. After shopping, meeting my friends is a relief as we chat a lot at McDonald's or a coffee shop. I love my friends! (Kati, 18)

In addition, the phenomenon that people ask strangers to share their coupons at the cashier and to pay off by cash is commonly accepted. In some cases, it is even considered an entertaining practice, which is highlighted by the following account:

I had a positive experience last year. I was standing at the cashier, and behind me there was a girl with an expensive leather jacket. She had already used her coupon and asked if I could give her mine. She then paid for my shirt too using my coupon, and we did the math afterwards. I gave her my coupon, so it was good for her as well. It was funny. At this time I like to fool a bit around even with strangers. (Panni, 26)

Two adult women reported to have made a written wish list on what they wanted to buy. One of them even shared her list online.

I always make a wish list of products that I will head for. And then I publish it on Facebook that this is what I will go for. Then, at the end, I also share the list of what I managed to buy. (Panni, 26)

The uniqueness of the Glamour days shopping phenomenon is that it has strong hedonic and utilitarian insights at the same time. As previous research concluded, the utilitarian aspect of a shopping trip "evoke value by successfully accomplishing an intended goal or by providing enjoyment and/or fun" (Babin et al. 1994: 645). Because of the economic savings provided by the coupons certain goals are set e.g. which items to buy. All respondents agreed that there is a priority list of shops and items, so they make sure that their top goals/items are accomplished and can relax and enjoy the rest of the Glamour Days shopping.

Sometimes I went to 3-4 different H\&M stores to find the right size [...] When I go with my sister, we go separately on Friday to get the high priority stuff, if shade or size is important, and then we go back together on Saturday to look around and do some more shopping. I am a hardcore researcher, and I love it. (Rita, 26) 
This year I wanted to buy this [shows the bag besides her] blue handbag from H\&M. On Friday, after work, I went to the shop, but there were so many people that I turned around [...] Then I saw that there is only one piece left, and that's a must have item. So I stood in line for more than 40 minutes. (Rita 26)

In contrast, planning did not forecome as a major theme for young adults and adolescents. They did not tend to plan what they were going to buy on Glamour Days. They were more likely to visit the stores they shop at on a regular basis, and avoided places they were not familiar with. In this sense, adolescents view Glamour Days as a perfect opportunity to obtain products, such as clothes or makeup, at lower prices at their favourite shops.

Although I read through the coupon magazine and I know about the discounts, I usually go to the shops I know and where I buy clothes or cosmetics. Glamour Days are good because they allow me to buy things at lower prices at my favourite shops. That is it! (Fanni, 17)

\subsection{Self gifting}

Our results suggest that Glamour Days are strongly related to various forms of self-gifting among adult females. For adults, "participating in Glamour Days" is something that they deserve. One interviewee mentioned that she even rescheduled a weekend with her boyfriend as stated below:

Once we had a wellness weekend booked with my boyfriend, and I postponed it, because I realized that that weekend is the Glamour Days, and I am definitely going. (Barbi, 26)

Others already booked their calendars or even took a day off from work to maximize the pleasure in the retail environment by avoiding the crowd as much as possible, and also to ensure the success of purchasing the right sizes and models.

I rather take a day off from work on Friday, so that I can look around more conveniently [because of the crowd]. (Vera, 33) 
For both age groups, buying something nice for oneself is the driving motivation of the Glamour Days shopping trip. It focuses on enhancing women's self image by allowing consumers to buy new and trendy items at a discount. For adolescents, who receive money primarily from their parents, Glamour Days serve as a special event similarly to birthdays or Christmas, when they are allowed to buy presents for themselves. In this sense, Glamour Days provide ample opportunities for adolescents to spend more on clothes or accessories than they are allowed to under normal circumstances.

I like Glamour Days because I can buy things for me and my parents do not freak out at all! They allow me to buy anything, although they do not give that much money, but I can buy more things than I am usually allowed to. It is like my birthday or something... (Lili, 16)

Adult respondents - especially those with children- expect their family to understand and support them in making the most out of that day without feeling guilty about neglecting other social roles or Life Projects such as "being a responsible mother" for that time, as referred below:

It's a girls' program. Then there is no discussion that someone needs to babysit my little brother. Even men can survive these two days a year when we go [with her Mom to the Glamour Days]. (Eszter, 26)

I'd rather buy for myself. Honestly, I've never even considered buying anything for my son $[\ldots]$ It is, let's say, a girls' program, so it [Glamour Days] is all about me. It may seem a bit egoistic, but it's MY day. I select things for myself. (Vera, 33)

Some adults even described these days as a race, as elaborated by one of the interviewees below:

I love the "big sales-go fight" type of feeling [...] Once, like in the movies, I grabbed a bag that another woman also held, started to pull it and I won. It is one of my favourite bags as I fought for it. (Timi, 32) 
Interestingly, compared to adult consumers, young adults and adolescents do not tend to view Glamour Days as race-like events, but rather as stressful ones when lots of people come together and the size of the crowd is nearly unbearable. As previously discussed, adolescents, who are often accompanied by their fellow friends or relatives, primarily consider Glamour Days a social event, therefore they find the extent of noise or the number of people disturbing that hinder social interactions. Under such circumstances, engaging in self-gifting practices may be quite challenging for adolescents who are striving for pleasurable social stimuli.

\footnotetext{
The crowd in Glamour Days is nearly unbearable [...] people are going crazy when they go to Glamour Days, I do not know why but they act like nuts [...] they just push each other and they are cursing all day long. Insane! Often I cannot hear my friends and I cannot have a good time because of the way people behave. (Olga, 19)
}

\subsection{Impulsive buying}

By reviewing a large amount of literature, the existence of a strong relation between selfgifting behaviour and self-indulgence can be established (Babin et al. 1994, Tauber 1972) which is supported also by our findings. As described previously, the "Glamour Shopping Day" itself is considered as a gift to oneself. All of our adult respondents agreed that they "plan on being impulsive" (Rook 1985). They set a budget based on their lists, but they are also mentally prepared to overspend without regret.

\footnotetext{
I mentally collect things that I need. There is always something extra that I will like, this is why I do not make lists. If I need it, that's even better, but if I just like it, I am happy because it was cheaper [laughs]. (Barbi, 26)
}

Of course we shop during the year as well, but I'd rather put it this way: we buy more on Glamour days, because then it is worth to buy [...] If it's necessary I ask my sister to lend me some more money [laughs]. (Gabi, 28)

Adolescents, on the other hand, who have a much smaller budget than their adult counterparts, are more sensitive to the prices, and therefore they try to avoid spending more money than they initially planned. However, they also reported that they were more likely to spend a little 
bit more on certain products, especially in the case of accessories or cosmetics, if they found something that they liked.

It is hard not to buy more things during Glamour Days [...]Usually I know what I want to buy, but I also buy other things too because sometimes I fall in love with clothes or a necklace, so I buy them too. (Éva, 18)

In addition, rationalization is another related dimension of combating post purchase regret. In the case of Glamour Days, the savings provided by the coupons help rationalize even substantial overspendings among adults as well as adolescent consumers. Below we provide some arguments as illustrations.

When I think of the Glamour days, the first thing that comes into my mind is the discount. Obviously I would buy them [clothes etc.] anyways, but it is a much better feeling if I buy them at a discount. So I try to write a longer list so that the saving will be greater as well. (Rita, 28)

On everyone's mind, Glamour Days Coupons are equal with "having to go shopping", because there is a coupon. They buy everything except what they need. I do it as well. I wanted to buy flat shoes and ended up with high heels from a shop that was not even in the coupon book [...] So it is not logical at all. (Panni, 26)

A more prevalent context was also delaying self gratification. $40 \%$ of the participants reported that they do "wait out" until the Glamour Days start, especially with high value items. This behaviour is possible because in most shops all items are on sale, so one can browse in advance without purchase intensions and buy it later during the Glamour Days sales.

Although I did not want to buy certain clothes or make-up first, I changed my mind and bought them because Glamour Days are just twice a year and by using coupons you are able to get these things at lower prices. (Júlia, 17)

\section{Managerial implications}

The present research highlighted the fact that a well designed retail activity may have substantial impact on consumers' relationship to hedonic shopping experience despite strong 
cultural or historical influence. As "retail therapy" accompanied by self gifting remains a strong driving force for retailer growth, it is essential to find ways to provide an ambiance which may contribute to changing customers' attitudes towards the preference of more hedonic shopping values and thus towards higher engagement in self gifting and impulse purchasing which in return drive retail growth.

At the same time for companies, it is necessary to know the behaviour and decision making process of these customers in order to succeed. A trial-and-error bases might as well cost the brand a loss of brand value. Consumers strategically plan the whole Glamour Shopping Day in advance, therefore if there is no coupon, the brand is not a part of the wish list or the shopping route. Consumers also compare coupon conditions, and as most brands offer $20 \%$ off from the overall shopping value, retailers which negatively diverge from this strategy are unfavourably differentiated in the minds of consumers (The Body Shop interview 2014). By understanding the different groups of consumers and identifying their motivational drivers, our results provide support for a well-designed sales strategy. Figure 1. provides strategic implications for brands considering the underlying consumer motivational aspects.

Figure 1. Strategic implications of the Glamour Days shopping experience for adult consumers

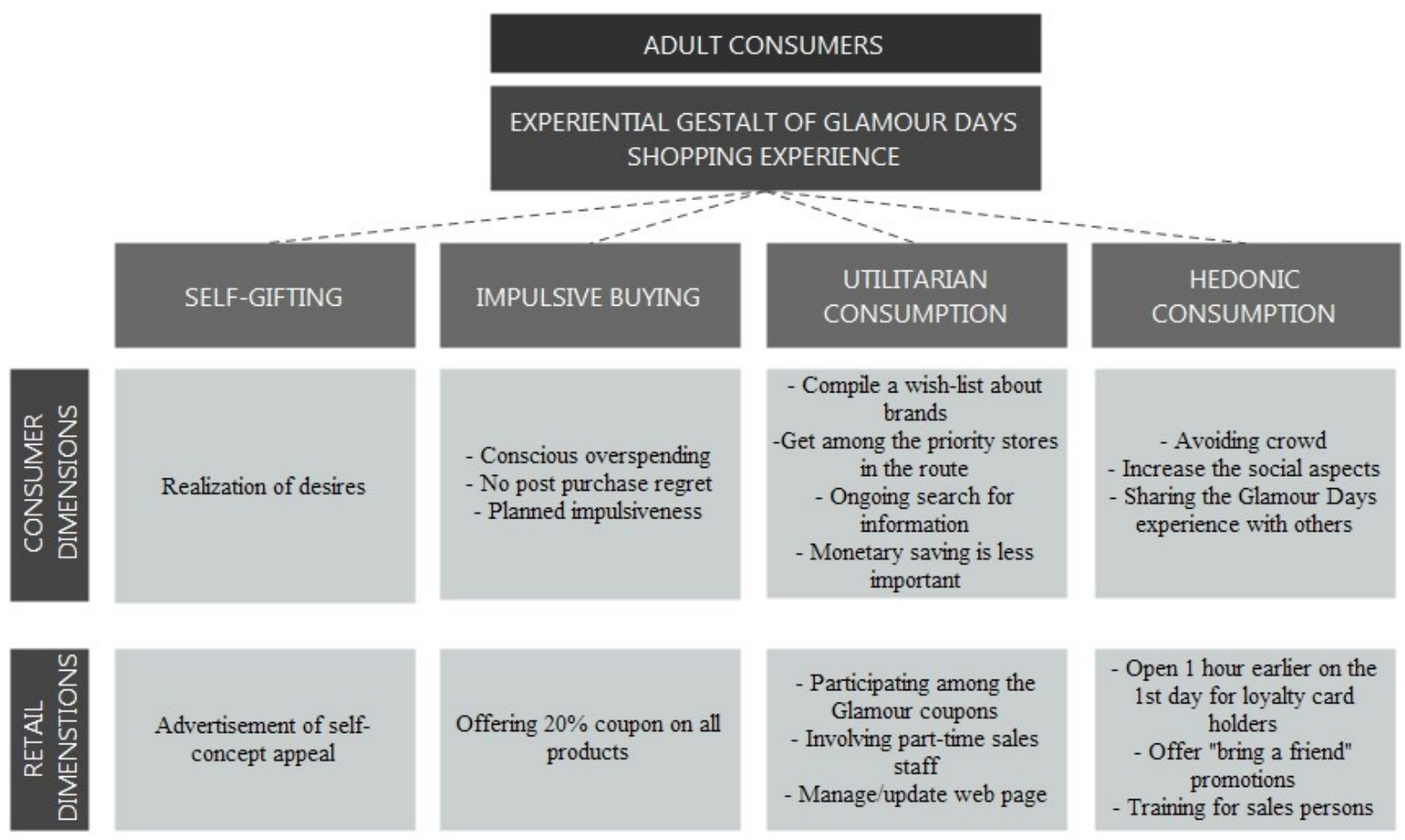

Source: authors 
The four pillars of the Glamour Days shopping phenomenon are self gifting, impulse buying, utilitarian, and hedonistic values. Participating firms targeting adult women can maximize their competitive advantage by building their retail tactics considering the underlying consumer expectations. Advertisements prior to the event should focus on the self concept, and emphasizing how the brand can enhance self esteem. Consumers are aware and consciously accept the fact that despite having a budget, overspending is a practice. They also admit to buying many unnecessary items, but they do not have post purchase regret, rather rationalizing it with the fact that they bought it at a discount. They plan impulsiveness. Therefore, if firms offer the coupons only for specific items, consumers will not engage in impulsive buying, but rather execute purchasing as a task oriented activity. Thus it is recommended that brands offering $20 \%$ off on all items purchased to drive impulsiveness and growth of sales. Utilitarian and hedonistic values are uniquely combined during this event. Consumers compile a wish list with desired brands and products and plan a priority route to each shop. Firms, to take maximum advantage of this "second Christmas" sales, must participate in the Magazine's Coupon Book to get into the consumer's planning process. Brands may use this opportunity to build their brand image by performing well under extreme conditions such as crowd and system of coupons. Sufficient number of sales people seemed to be the bottleneck of the perceived performance, thus part time sales staff is advised for these three days. Some consumers expressed disappointment in brands that did not deliver as expected on these terms. Websites serve as important sources for gathering information, therefore updated and well functioning web pages can increase the utilitarian value experienced by shoppers. Although monetary savings are important, hedonistic and social dimension is more important to Glamour Day shoppers. They tend to share their experience and their "prizes" with friends and relatives. As all of our interviewees described the crowd as a very negative factor, firms may offer ways for loyalty card holders to avoid crowds by, for example, offering 1 hour early entry to the shop. "Bring a friend" type of promotions may enhance the social aspect of the experience. 
Figure 2. Strategic implications of the Glamour Days shopping experience for teenagers TEENAGER CONSUMERS

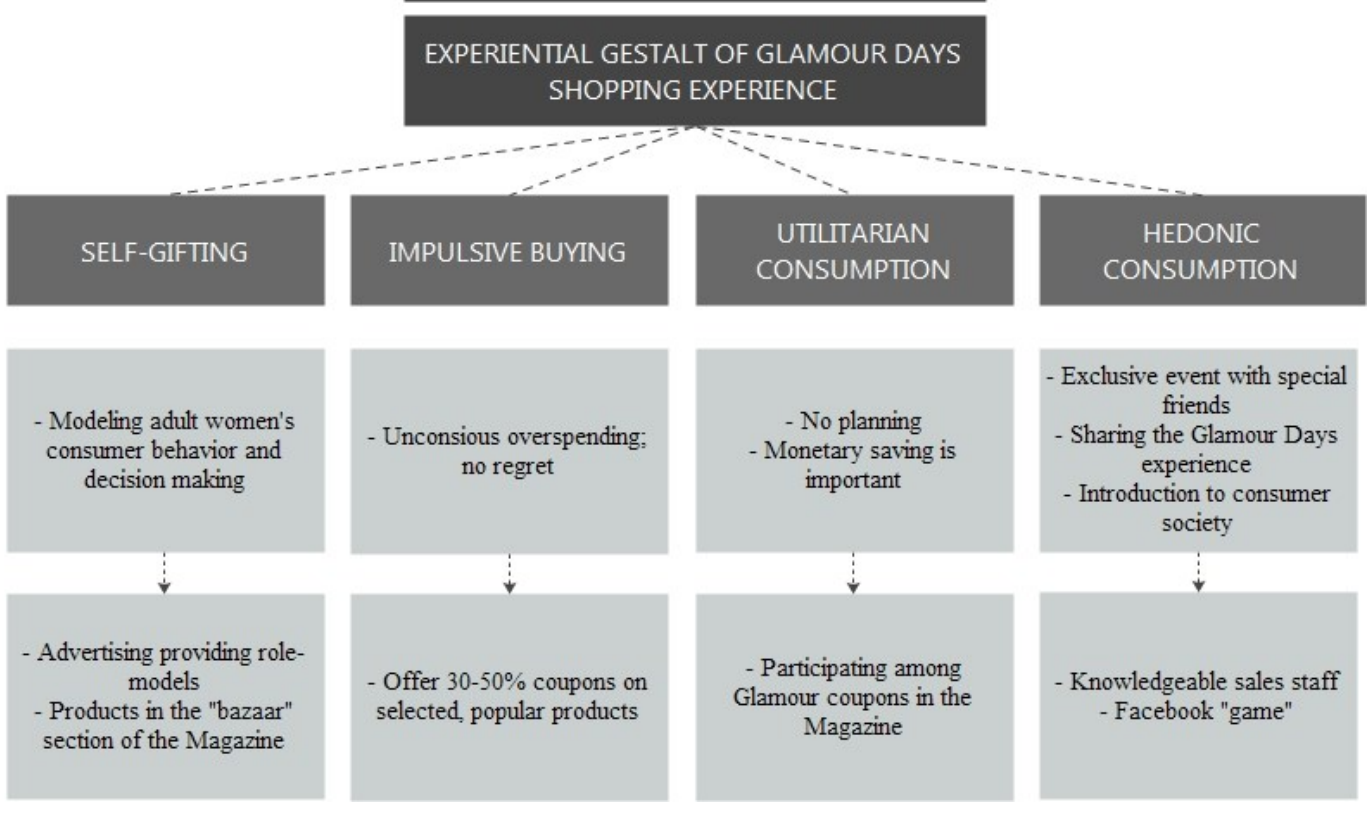

Source: authors

For brands targeting teenagers, a slightly different approach is needed (Figure 2). They also buy self gifts, but it is less conscious than among adults. Advertising should focus on providing female role models as teenagers consider this event as an introduction to womanhood and they model the behaviour and decision making of adult women. For positioning brands in young adults' minds, product or brand constellations in the "bazaar" section of magazines is advised. Although teenagers also have a budget, impulsive buying is unconsciously present. Firms may offer higher discounts on selected popular items, as peer pressure and conforming to group is much stronger within this consumer group. In contradiction with adult women, discounts were considered as the most important utilitarian value resulting in monetary savings and hedonic aspects were less important. The Glamour Days shopping experience was still considered as an exclusive event which gave them an opportunity to differentiate themselves within their peer groups and as an early introduction to the Life Theme "being cosmopolitan". Retailers may offer games on Facebook to share this experience and connect this group of consumers to their brands.

\section{Conclusion}

Previous studies on self-gifting, hedonic and utilitarian shopping and impulse buying mostly focused on the internal urge of the customer to satisfy these needs (e.g. Coley - Burgess 2003; 
Babin et al. 1994; Rook 1987). The present study introduces a retail phenomenon which influenced the cultural ideology and the behaviour of consumers at a self conceptual level. Literature review and also phenomenological narratives suggest that the hedonistic and utilitarian shopping experience constitutes a meaningful behaviour under different Life Projects (Huffman et al. 2000). The study covers the investigation of the motivational drivers of joining the Glamour Days within two distinct consumer groups: adult women and young adults (teenagers). The research contributes with new insights on how new cultural beliefs about consumption changed the role of consumption in everyday life in the post socialist period, providing opportunity to a well focused retail phenomenon like Glamour Days. Understanding the dynamics of hedonistic and utilitarian shopping of this special group of consumers, suggest a changing trend in women's involvement in shopping. In reflection of the social context within consumers' self gift related shopping experiences, the role of impulse buying provides managerial implications for new retail strategies.

In conjunction with previous research findings, hedonistic and utilitarian values coexist in shopping experiences. The Glamour Days shopping experience uniquely combines these two values described by the participants. The phenomenological interview results concluded that the motivational drivers for pleasure-oriented shopping were different within the two sample groups. For teenagers, the main motivation was related to the utilitarian aspect due to their financial dependence and therefore the value provided by the discounts, accompanied by the special opportunity to stand out of their peer group by joining an event mostly saved for adult women. Therefore, the focus was on sharing this experience with their close friends without substantial planning of the trip.

For adult women, the day itself was "reserved" as a self gift independently from the context of present life situation. The more this special occasion of a well deserved shopping trip was reflected within the motivation of joining this event, the more time management as a utilitarian aspect emerged. Adult women therefore preferred to go alone or chose their companionship carefully so the previously described value could be upheld. An interesting result emerged, for mothers with young children: the psychological state of possibly feeling guilty about focusing on their role as a woman instead of the mother, by taking a day out for shopping only for them, was dismissed. It was expressed rather as an expectation from their environment to support their well deserved hedonic shopping trip. 
In the case of young consumers, parents and older sisters have a significant impact on young adults' previous shopping experience on Glamour Days. This shopping event may be considered as a stage of consumer socialization that teaches them how to use coupons and how to find what they want among dozens of brands and products. In a later life stage this tendency may turn reverse as some adult women preferred to go with their mothers to help them with the choice and to spend quality time together.

The hedonistic appeal of Glamour Days is reflected also by the psychological waiting and preparation within this group of consumers. Women tended to cut out the coupons in advance, organize them, even visit the stores before the event to try clothes on, so that during Glamour Days they can avoid wasting time by standing in multiple lines. Impulse buying is planned and accepted during these days. As a result, the possible psychological disequilibrium related to impulse buying episodes (Rook - Hoch 1985) does not constitute in post purchase regret. Consumers are postponing their gratification by waiting for the Glamour Days to come, and therefore, a well-planned set of strategic moves secure the success of the purchase. The ambiguity of the hedonic motivation lies within the decision to go alone or only with a very limited number of friends and the willingness to cooperate with strangers within the stores. The social dimension is counterproductive for the adult women group. To make the most out of the day consumers prefer to be very effective, but at the same time, also want to share the feelings of "camaraderie" during the event. In addition, sharing coupons or even collaborating in paying jointly with strangers is a common practice. For young adults, the social interaction constitutes of going out with friends and enjoying being independent from their families while shopping for themselves. The young adult sample confirmed that Glamour Days provide an opportunity to buy image related products with their peer group that are not reachable for them otherwise.

By understanding the lived experience of the two age groups during Glamour Days highlights the changing socioeconomic context in Hungary. The qualitative research provides a solid base for future quantitative research whereby a deeper understanding of different participating consumer types and their behaviour could be investigated. The tendency for reciprocal socialization is evidently present and further research may deepen the understanding of its relevance to a new way of spending "quality time" in the post modern world. Finally, the result of the research provides possibility to transfer the concept of the Glamour days shopping event to other cultures as well. 


\section{References}

Alba, J. W. - Williams, E. F. (2013): Pleasure principles: A review of research on hedonic consumption. Journal of Consumer Psychology 23(1): 2-18.

Arnold, M. J. - Reynolds, K. E. (2012): Approach and Avoidance Motivation: Investigating Hedonic Consumption in a Retail Setting. Journal of Retailing 88(3): 399-411.

Babin, B. J. - Darden, W. R. - Griffin, M. (1994): Work and/or Fun: Measuring Hedonic and Utilitarian Shopping Value. Journal of Consumer Research 20(4): 644-656.

Bashar, A. - Ahmad, I. -Wasiq, M. (2013): A Study of Influence of Demographic Factors on Consumer Impulse Buying Behavior. Journal of ManagementResearch 13(3): 145-154.

Bauer, A. - Mitev, A. (2012): The Effect of Attitude Toward Money on Financial Trouble and Compulsive Buying: Studying Hungarian Consumers in Debt During the Financial Crisis. In: Diamantopoulos, A. - Fritz, W. - Hildenbrandt, L. (Eds.): Quantitative Marketing and Marketing Management -Marketing Models and Methods in Theory and Practice. London: Springer-Verlag.

Bayley, G. - Nancarrow, C. (1998): Impulse purchasing: a qualitative exploration of the phenomenon. Qualitative Market Research: An International Journal 1(2): 99-114.

Belk, R. (1987): A Child's Christmas in America: Santa Claus as Deity, Consumption as Religion. Journal of American Culture 10(1): 87-100.

Brici, N. - Hodkinson, C. - Sullivan-Mort, G. (2013): Conceptual differences between adolescent and adult impulse buyers. Young Consumers 14(3):258-279.

Boyd, C. O. (2001): Phenomenology the method. In: Munhall, P. L. (ed.): Nursing research: A qualitative perspective. Sudbury: Jones and Bartlett.

Carpenter, J. M. - Moore, M. (2009): Utilitarian and hedonic shopping value in the US discount sector. Journal of Retailing and Consumer Services 16(1): 68-74.

Chitturi, R. - Raghunathan, R. - Mahajan, V. (2008): Delight by Design: The Role of Hedonic Versus Utilitarian Benefits. Journal of Marketing 72(3): 48-63.

Clarke P. D. - Mortimer, G. (2013): Self-gifting guilt: an examination of self-gifting motivations and post purchase regret. Journal of Consumer Marketing 30(6): 472-483.

Colaizzi, P. (1978): Psychological research as a phenomenologist views it. In: Valle, R. King, M. (eds.): Existential Phenomenological Alternatives for Psychology. New York: Oxford University Press.

Coulter, R. - Price, L. - Feick, L. (2003): Rethinking the origins of involvement and brand commitment: Insights from postsocialist Central Europe. Journal of Consumer Research 30(2): 151-169. 
Coulter, R. - Price, L. - Feick L. - Micu, C. (2005): The evolution of consumer knowledge and sources of information: Hungary in transition. Journal of the Academy of Marketing Science 33(4): 604-609.

Creswell, J. W. (1998): Qualitative inquiry and research design: Choosing among five traditions. Thousand Oak: Sage.

Dhar, R. - Wertenbroch, K. (2000): Consumer Choice Between Hedonic and Utilitarian Goods. Journal of Marketing Research 37(1): 60-71.

Droge, C. - Mackoy, R. D. (1995): The consumption culture versus environmentalism: Bridging value systems with environmental marketing. In: Ellen, P. S. - Kaufman, P. (eds.) Proceedings of the 1995 Marketing and Public Policy Conference. Atlanta: Georgia State University Press.

Eroglu, S. - Harrell, G. D. (1986): Retail Crowding: Theoretical and Strategic Implications. Journal of Retailing 62(4): 346-363.

Fischer, E. - Arnold, S. J. (1990): More than a Labor of Love: Gender Roles and Christmas Shopping. Journal of Consumer Research 17(3): 333-345.

Goldsmith, K. - Cho, E. K. - Dhar, R. (2012): When Guilt Begets Pleasure: The Positive Effect of a Negative Emotion. Journal of Marketing Research 49(6): 871-882.

Heath, M. T. - Tynan, C. - Ennew, C. T. (2011): Self-gift giving: understanding consumers and exploring brand messages. Journal of Marketing Communications 17(2): 127-144.

Hirschman, E. C. - Holbrook, M. B. (1982): Hedonic Consumption: Emerging Concepts, Methods and Propositions. Journal of Marketing 46(3): 92-101.

Holman, R. H. (1981): Apparel as Communication, in Symbolic Consumer Behavior. In: Hirschman, E. C. - Holbrook, M. B. (eds.): Symbolic Consumer Research. Ann Arbor: Association for Consumer Research.

Huffman, C. - Ratneshwar, S. - Mick, D. G. (2000): Consumer Goal Structures and GoalDetermination Processes: An Integrative Framework. In: Ratneshwar, S. - Mick, D. G. - Huffman, C. (eds.): The Why of Consumption: Contemporary Perspectives on Consumer Motives, Goals, and Desires. London: Routledge.

Hycner, R. H. (1999): Some guidelines for the phenomenological analysis of interview data. In: Bryman, A.- Burgess, R. G.(eds.):Qualitative research. London: Sage.

Kauppinen-Räisänen, H. - Finne, Å. - Gummerus, J. - Helkkula, A. - Koskull, C. Kowalkowski, C. - Rindell, A. (2014): Am I worth it? Gifting myself with luxury. Journal of Fashion Marketing \& Management 18(2): 112-132. 
Leigh, J. H. - Gabel, T. G. (1992): Symbolic interactionism: its effects on consumer behaviour and implications for marketing strategy. Journal of Consumer Marketing 6(3): 27-38.

Mick, D. G. - DeMoss, M. (1990): Self gifts: phenomenological insights from four contexts. Journal of Consumer Research 17(3): 322-332.

Mick, D. G. - DeMoss, M. - Faber, R. J. (1992): A projective study of motivations and meanings of self-gifts:implications for retail management. Journal of Retailing 68(2): 122-144.

Millan E. S. - Howard E. (2007): Shopping for pleasure? Shopping experiences of Hungarian consumers. International Journal of Retail \& Distribution Management 35(6): 474 487.

Neuner, M. - Raab, G. - Reisch, L.A. (2005): Compulsive buying in maturing consumer societies: An empirical re-inquiry. Journal of Economic Psychology 26(4): 509-522.

Rohatyn, D. (1990): The (mis)information society: an analysis of the role of propaganda in shaping consciousness. Bulletin of Science: Technology and Society 10(2): 77-85.

Rook, D. W. (1987): The Buying Impulse. Journal of Consumer Research 14(2): 189-99.

Rook, D. W. - Hoch, S. J. (1985): Consuming Impulses. In: Hirschman, E. C. - Holbrook, M. B. (eds.). Advances in Consumer Research. Provo: Association for Consumer Research.

Sherry, J. F. Jr. (1983): Gift Giving in Anthropological Perspectiwe. Journal of Consumer Research 10(2): 157-168.

Sherry, J. F. Jr. (1990): A Sociocultural Analysis of a Midwestern Flea Market.Journal of Consumer Research 17(1): 13-30.

Sivadas, E. - Venkatesh, R. (1995): An Examination of Individual and Object-Specific Influences on the Extended Self and its Relation to Attachment and Satisfaction. Advances in Consumer Research 22(1): 406-412.

Solomon, M. R. (1983): The role of products as social stimuli: a symbolic interaction perspective. Journal of Consumer Research 10(3): 319-29.

Spiegelberg, E. (1981): The Phenomenological Movement: A Historical Introduction. London: Springer.

Tauber, E. M. (1972): Why do People Shop? Journal of Marketing36(4): 46-49.

Thompson, C. J. - Locander, W. B. - Pollio, H. R. (1990): The lived meaning of free choice: An existentialphenomenological description of everyday consumer experiences of contemporary married women. Journal of Consumer Research 17(3): 346-362. 
Thompson, C. J. (1996): Caring Consumers: Gendered Consumption Meanings and the Juggling Lifestyle. Journal of Consumer Research 22(4): 388-407.

Wagner, T. - Rudolph, T. (2010): Towards a hierarchical theory of shopping motivation. Journal of Retailing and Consumer Services 17(5): 415-429.

Wakefield, K. L. - Baker, J. (1998): Excitement at the Mall: Determinants and Effects on Shopping Response. Journal of Retailing 74(4): 515-39.

Ward, C. - Thuhang, T. (2012): Consumer gifting behaviors: one for you, one for me? Services Marketing Quarterly 29(2):1-17.

Woodruffe-Burton, H. - Wakenshaw, S. (2011): Revisiting experiential values of shopping: consumers' self and identity. Marketing Intelligence \& Planning 29(1): 69-85.

Zhong, J. Y. - Mitchell, V. W. (2012): Does Consumer Well-Being Affect Hedonic Consumption? Psychology \& Marketing 29(8): 583-594. 